\title{
SERUM MALONDIALDEHYDE AS PREDICTOR OF OXDATIVE STRESS IN EARLY RHEUMATOID ARTHRITIS.
}

\author{
Zunaira Azher ${ }^{1}$, Iqra Altaf ${ }^{2}$, Anam Javed Mirza ${ }^{3}$ \\ 1. House Officer Sheikh Zaid Medical College Rahm Yar Khan \\ 2. House Officer Quid E Azam Medical College Bahawalpur \\ 3. House Officer Lahore General Hospital, Lahore
}

\begin{abstract}
:
Objective: To measure the concentration and role of malondialdehyde to determine oxidative stress in rheumatoid arthritis patients and comparing them with healthy individuals. Methodology: This cross sectional study was conducted on 180 patients of age 49 to 70 years and both gender. Study was completed in the department of physiology Sheikh Zaid Medical College, Quid e Azam Medical college and Lahore General Hospital, from October 2017 to October 2018. Study was started after obtaining ethical approval and informed consent from the patients. SPSS version 23 was used to analyze data related to study. Continuous variables were presented as mean and standard deviation like age and Serum MDA concentration, categorical variables were presented as numbers and percentages like gender. Post operative chi square test was applied and $p$ value less than or equal to 0.05 was considered as significant. Results: Overall, there were $100 \%(\mathrm{n}=180)$ patients were included, in this study. The study group was further divided into two equal groups, $50 \%(\mathrm{n}=90)$ in each, i.e. Rheumatoid arthritis (RA) group and control group. RA group patients include those diagnosed as rheumatoid arthritis clinically and through lab investigations and control group consist of normal healthy adults. The serum MDA levels in the RA patients were $3.97 \pm 1.03 \mathrm{nmoles} / \mathrm{ml}$ and it was $1.59 \pm 0.32 \mathrm{nmol} / \mathrm{ml}$ in control patients. The difference was statistically significant $(\mathrm{t}=20.87, \mathrm{p}=0.001)$. Conclusion: the observations of our study showed statistically significant raised serum Malondialdehyde level as compared to control group.
\end{abstract}

Keywords: Malondialdehyde, Rheumatoid arthritis, Lipid per oxidation, Free radicals.

DOI: $10.7176 / \mathrm{JMPB} / 55-18$

Publication date:May $31^{\text {st }} 2019$

\section{Introduction:}

An inflammatory disease Rheumatoid Arthritis has capability of continuous destruction of synovial joints. This condition also known as synovitis which may include deterioration of bones and cartilage, some other are systemic like pulmonary, cardiovascular, psychological and skeletal system abnormalities. Prevalence of rheumatoid arthritis reported as $1 \%$ in literature worldwide ${ }^{1}$.

Malondialdehyde (MDA) is a main contributing factor of DNA mutation in human and bacterial cells, it produces as a result of lipid peroxidation and also from biosynthesis of prostaglandins. MDA also reported as carcinogenic agent as reported in some studies conducted on rats. It was also reported that in Salmonella typhimurium MDA responsible for their gene mutation by affecting base substances. In Escherichia coli replication was observed on single standard M13 genome mutation $(\mathrm{G} \rightarrow \mathrm{T}, \mathrm{A} \rightarrow \mathrm{G}$, and $\mathrm{C} \rightarrow \mathrm{T})$. These three modifications are possible in DNA as a result of MDA involvement. It was separated from tissues of healthy humans in form of $\mathrm{M} 1 \mathrm{G}$ which was produced as a result of reaction with guanine ${ }^{2}$.

Cytokinesand $\mathrm{T}$ cells in combination with oxygen radicals and hydrogen peroxide plays major role in progressive activity of macrophages and enhancement of Rheumatoid Arthritis. Nitrogen and oxygen species have both types of effects beneficial and harmful ${ }^{3}$. Increased level of malonaldehyde (oxidative stress) is stage when reactive nitrogen and oxygen reaches to a damaging range and harm the cells and other biological body markers. When body's mechanism of antioxidants and oxidative stress become imbalance it can cause serious autoimmune diseases like Rheumatoid Arthritis ${ }^{4}$. Oxygen species in reactive form plays an important role in $\mathrm{RA}$, main attack of these reactive oxygen molecule is unsaturated fatty acids.

They damage nucleic acid, connective tissue and lipids of cell membrane, as a result of these damage free radicals and their result products cause inflammation by realizing mediators ${ }^{5}$. In synovial joints, synovial fluids have chemo attractant property; this property leads to the anaerobic glycolysis and enhancement the oxygen consumption. This whole activity generates hydroxyl, hypochloricradicals and superoxide. Among all these components neutrophils are found to be active in synovial fluid and cause erosion when Rheumatoid Arthritis develops ${ }^{6}$. 
In lipid peroxidation malondialdehyde is an important factor and hallmark of Rheumatoid Arthritis diagnosis ${ }^{7}$. In recent studies it was observed and suggested that early and right management of malondialdehyde reduced and delayed the incidence of Rheumatoid Arthritis. Vyas S et $\mathrm{al}^{8}$ conducted a study in 2016 and observed a significant increase in malondialdehyde level in serum of Rheumatoid Arthritis patients; $p$ value was 0.0001 which is significant. Determine the serum malondialhyde level in Rheumatoid Arthritis patients and to compare with normal and healthy patients is objective of our study ${ }^{9}$.

\section{Methodology:}

This cross sectional study was conducted on 180 patients of age 49 to 70 years and both gender. Study was completed in the department of physiology Sheikh Zaid Medical College, Quid e Azam Medical college and Lahore General Hospital, from October 2017 to October 2018. Study was started after ethical approval from institutions committee of ethics. Patients were divided into two equal groups ( 90 patients in each group). Non probability consecutive sampling technique was used. Sample size was calculated by using openepi.com an online source for sample size calculation. Complete physical examination, routine laoratoryand radiological investigations was done. Rheumatoid arthritis was confirmed by X ray, c reactive protein, antinuclear antibody and rheumatoid arthritis factor. Patients of normal healthy diet, no history of nutritional supplement and post and pre menopausal women were included in the study. Patients with known history of diabetes, hypertension, smokers, alcoholic, history of anti inflammatory dugs and any trauma to joint were excluded from the study. With all antiseptic measures $5 \mathrm{ml}$ blood was drawn from anticubetal vein and sent to laboratory for laboratory investigation. Sampling tube was opened with care to avoid hemolysis. Blood was allowed to clot at room temperature for some time than serum was drawn after centrifugation (centrifugation was done at $3000 \mathrm{rpm}$ for 15-20 minutes in morning shift. Hemolytic samples were discarded. Thiobarbituric acid assay test was used to estimate MDA concentration. UV-VIS Spectrophotometer was used to calculate optical density. Thiobarbituric acid assay method measures Malondialdehyde by measuring aldehyde products of lipid peroxide. Exact mechanism behind this procedure is reaction of two molecules of thiobarbituric acid and one molecule of Malondialdehyde to make MDA-TBA red product which can be measured at $535 \mathrm{~nm}$.

SPSS version 23 was used to analyze data related to study. Continuous variables were presented as mean and standard deviation like age and Serum MDA concentration, categorical variables were presented as numbers and percentages like gender. Post operative chi square test was applied and p value less than or equal to 0.05 was considered as significant.

\section{Results:}

Overall, there were $100 \%(n=180)$ patients were included, in this study. The study group was further divided into two equal groups, $50 \%(\mathrm{n}=90)$ in each, i.e. Rheumatoid arthritis (RA) group and control group. The Mean \pm S.D age of RA patients was $54.61 \pm 4.61$ years. While, the Mean \pm S.D age of the control patients was $50.0 \pm 4.23$ years. The difference was statistically significant $(\mathrm{t}=6.98, \mathrm{p}=0.000)$. Gender distribution, in RA patients, was observed as $58.9 \%(n=53)$ males and $41.1 \%(n=37)$ females. While, in control patients, there were $48.9 \%(n=44)$ males and $51.1 \%(n=46)$ females. The difference was statistically insignificant $\left(\chi^{2}=1.81, p=0.178\right)$ (Table. 1).

The serum MDA levels in the RA patients were $3.97 \pm 1.03 \mathrm{nmoles} / \mathrm{ml}$ and it was $1.59 \pm 0.32 \mathrm{nmol} / \mathrm{ml}$ in control patients. The difference was statistically significant $(\mathrm{t}=20.87, \mathrm{p}=0.000)$. (Table. 2$)$.

Table. 1

Demographic characteristics of RAandcontrol patients

\begin{tabular}{|c|c|c|c|}
\hline Characteristics & $\begin{array}{c}\mathbf{R A}^{*} \\
(\mathbf{n = 9 0})\end{array}$ & $\begin{array}{c}\text { control } \\
(\mathbf{n = 9 0})\end{array}$ & Test of Sig. \\
\hline Age & $54.61 \pm 4.61$ years & $50.0 \pm 4.23$ years & $\mathrm{t}=6.98, \mathrm{p}=0.000$ \\
\hline Gender & $\mathrm{M}=58.9 \%, \mathrm{~F}=41.1 \%$ & $\mathrm{M}=48.9 \%, \mathrm{~F}=51.1 \%$ & $\chi^{2}=1.81, \mathrm{p}=0.178$ \\
\hline
\end{tabular}

* Rheumatoid arthritis

Table-2 
Mean Serum MDA concentration (nmoles/ml) in RA patients with that of controls

\begin{tabular}{|c|c|c|c|}
\hline $\begin{array}{c}\text { Mean Serum MDA } \\
\text { concentration }\end{array}$ & $\begin{array}{c}\mathbf{R A}^{*} \\
(\mathbf{n}=\mathbf{9 0})\end{array}$ & $\begin{array}{c}\text { Control } \\
(\mathbf{n}=\mathbf{9 0})\end{array}$ & Test of Sig. \\
\hline Mean \pm S.D & $3.97 \pm 1.03 \mathrm{nmoles} / \mathrm{ml}$ & $1.59 \pm 0.32 \mathrm{nmol} / \mathrm{ml}$ & $\mathrm{t}=20.87, \mathrm{p}=0.000$ \\
\hline
\end{tabular}

* Rheumatoid arthritis * Malondialdehyde

\section{Discussion:}

Rheumatoid arthritis may be due to increased level of oxidative stress and serum MDA. After this continuous increase in MDA, chain reaction starts which gives continuous free radicals for continuation and new cycle of per oxidation. This whole cycle produced a new mixture of MDA. In many previous studies level of MDA observed increased in rheumatoid arthritis patients as compare to normal adults ${ }^{10}$.

In our study it was observed that in RA patients there was $58.9 \%(n=53)$ males and $41.1 \%(n=37)$ females. RA was found in most of male patients. A similar study was conducted by Vyas S et al ${ }^{8}$ on Indian population in 2016 and reported that RA was mostly found in female patients. In his study 16 male were diagnosed with RA and 34 female. Findings of his study show that RA was common in female as compared to male population in India. These results are against our findings. In another study Fridlyand LE et al ${ }^{9}$ also reported similar results that RA was mostly diagnosed in female subjects as compare to male and main contributing factor is increase in Malondialdehyde. Results of this study are also against our results and in favor of study conducted by Vyas S et al. Post menupausal arthritis changes in female patients were also assessed in some studies but thatis contributing factor of old age female. Malondialdehyde was found in all age groups.

In our study in RA patients serum MDA found to be increased when compared with controls. Serum MDA levels in the RA patients were $3.97 \pm 1.03 \mathrm{nmoles} / \mathrm{ml}$ and it was $1.59 \pm 0.32 \mathrm{nmol} / \mathrm{ml}$ in control patients. The difference was statistically significant $(\mathrm{t}=20.87, \mathrm{p}=0.000)$. Our results similar to study conducted by Gambhir $\mathrm{JK}$ et al ${ }^{11}$ in 1997 who found increased level MDA in serum of rheumatoid arthritis patients as compared to healthy controls, $\mathrm{p}<0.001$.

Similar studies were conducted by Mane KK et $\mathrm{al}^{12}$ in 1999 and Vyas $\mathrm{S}$ et $\mathrm{al}^{8}$ in 2016 and reported increased level of MDA in serum of rheumatoid arthritis patients. This increased serum MDA due to increased production of free radicals and oxidative stress in rheumatoid arthritis patients. Result of these two studies identical to our findings.

Moti L Tiku ${ }^{13}$ and Jaswal S et $\mathrm{al}^{14}$ also conducted similar studies and reported that free radical production and peroxidation was found in patients of rheumatoid arthritis and osteoarthritis patients. These studies were also in favor of our findings. A study by Karatas $\mathrm{F}$ et $\mathrm{al}^{15}$ also supports our findings.

Similarly studies conducted by Paliwal MN et al ${ }^{16}$ and Maneesh et a ${ }^{17}$ and reported similar results to our study. They found increased serum enzymatic antioxidant marker and lipid MDA as compare to healthy controls $\mathrm{P}<$ 0.05. Results of these studies were significant and comparable to our results. Another similar study was conducted by El-barbary AM et $\mathrm{al}^{18}$ and reported similar finding.

In our study we found that serum Malondialdehyde level was increased in patients of rheumatoid arthritis, similar results were reported by Lunec et al in his study, he revealed that serum uric acid concentration found to be increased in serum and synovial fluid of RA patients ${ }^{19}$. Another study was conducted by Gambriz et al in 1997 on topic of serum uric acid level in RA patients and reported that increase in serum uric acid concentration are the cause of RA specifically in aged patients ${ }^{20}$. Another similar study was conducted by Chaturvedi et al 1990 and reported similar finding that serum uric acid was increased in RA patient's blood. Findings of these studies are comparable with our findings and goes in favor of our results ${ }^{21}$.

\section{Conclusion:}

the observations of our study showed statistically significant raised serum Malondialdehyde level as compared to control group.

\section{References:}


1. Scott JT. Arthritis and Rheumatism: The Facts. Oxford: Oxford UP, Print. Scott, Jennifer 2007; 3:698706.

2. S 'wierkot J, Mie dzybrodzki R. The meaning of the methotrekseta in monotherapy and multipletherapy in patients with rheumatoid arthritis. Terapia nr 2005; 3:164.

3. Desai Prakash B, Manjunath S, KadiSumangala K, Chetana, Vanishree J. Oxidative stress and enzymatic antioxidant status in RA: a case control study. Eur Rev Med Pharmacol Sci 2010; 14:959-67.

4. Hegemann NB, Kohn L, Brnnberg, Schmidt MF. Osteoarthritis Cartil 2002; 10:714-21.

5. Halliwell B, Chirico S. Lipid peroxidation, its mechanism, measurement and significant. Am J Clin Nutr 1993; 57:7155-245.

6. Raharjo S, Sofos JN, Schmitt GR. Solid phase acid extraction improves thiobarbituric acid methods to determine lipid oxidation. J Food Sci 1993; 58:921-4.

7. Yu BP. Cellular defense against damage from reactive oxygen species. Physiol Rev 1994; 74:139-62.

8. Vyas S, Sharma H, RK V. Role of malondialdehyde in the serum of rheumatoid arthritis and osteoarthritis. J Postgrad Med Inst 2016; 30(1): 58-61.

9. Fridlyand LE, Philipson LH. Oxidative reactive species in cell injury: Mechanisms in diabetes mellitus and therapeutic approaches. Ann N Y Acad Sci 2005;1066:136-51.

10. Buege JA, Aust SD. Microsomal lipid peroxidation. In:Fleicher S, Packer L, Eds. Methods in Enzymology. Acedemic press, NY. 1978; 52:302-10.

11. Gambhir JK, Lali P, Jain AK. Correlation between blood antioxidants levels and lipid peroxidation in rheumatoid arthritis. Clin Biochem 1997; 30:351-5.

12. Mane KK, Sardeshmukh AS, Rathi DB, Suryakar AN. Lipid peroxide and Antioxidants in arthritis. Med J West India 1999; 27:108-110.

13. Moti L, Tiku, Shah Rahul, Allison G. Evidence linking chondrocyte lipid peroxidation to cartilage matrix protein degradation. Possible role in cartilage aging and the pathogenesis of osteoarthritis. J Biol Chem 2000; 275: 20069-76.

14. Jaswal S, Mehta HC, Sood AK, Kaur J. Antioxidant status in rheumatoid arthritis and role of antioxidant therapy. Clin Chim Acta 2003; 338:123-9.

15. Karatas F, Ozates I, Canatan H, Halifeoglu I, Karatepe M, Colakt R. Antioxidant status \& lipid peroxidation in patients with rheumatoid arthritis. Indian J Med Res 2003; 118:178-81.

16. Paliwal MN, Sontakke AN, Paliwal P. Study of serum MDA \& reduced glutathione level in patients with Osteoarthritis 2013; 2:5682-7.

17. Maneesh M, Jayalekshmi H, Suma T, Chatterjee S, Chakrabarti A, Singh TA. Evidence for oxidative stress in osteoarthritis. Indian J Clin Biochem 2005; 20:129-30.

18. El-barbary AM, Khalek MAA, Elsalawy AM, Hazaa SM. Lipid peroxidants \& antioxidants status in Rheumatoid Arthritis and Osteoarthritis Patients. The Egypt Rheumatol 2011; 33:179-85.

19. Lunec J, Hollaran SD, white AG, Dormandy TL; "Free radical oxidation (peroxidation) products in serum and synovial fluid in RA". J Rheumatol 1981; 8:233 -245.

20. Gambhir JK, Lali P, Jain AK; "Correlation between blood antioxidants levels and lipid peroxidation in RA” Clin Biochem.1997; 30:351 -355.

21. Chaturvedi V, Handa R, Rao DN, Wari JP; "Estimation and significance of serum and synovial fluid MDA levels in RA”. Ind J med Res.1999; 109:170 -174. 